\title{
Cenas de um Processo de Aquisigão e de Aprendizagem da Língua Francesa por um Falante Nativo da Variante Brasileira do Português: $U_{m}$ Estudo de Caso
}

\author{
Maranúbia Pereira BARBOSA \\ (PPGEL-UEL) \\ Adja Balbino de Amorim Barbieri DURÃO
}

(UEL)

Resumo: Este artigo trata de alguns aspectos da aquisição/ aprendizagem de um falante nativo de português brasileiro, cujo aprendizado de língua francesa se deu no país onde essa língua se originou, a França. Inserido diretamente no contexto estrangeiro, esse informante exemplifica o complexo processo de aquisição/ aprendizagem de uma segunda língua, no tocante a aspectos lingüísticos e socioculturais. Tendo como base a análise descritiva do português (L1) e do francês (L2), assim como a descrição das dificuldades do sujeito-informante, este estudo se pauta sobre os pressupostos da Lingüística Contrastiva (LC). Estabelece como prioridade o contraste entre sistemas lingüísticos e culturais, tendo por finalidade a observação de eventuais desvios e bloqueios, classificando-os de acordo com suas características. Expõe, ainda, os aspectos mais relevantes das dificuldades vivenciadas pelo sujeito-informante, na tentativa de apresentar a professores e pesquisadores da área algumas situações reais que cercam os processos de aquisição e aprendizado de uma língua estrangeira.

Palavras-chave: Lingüística Contrastiva; aquisição/aprendizagem de segunda língua; análise descritiva e comparativa do Português e do Francês

Abstract: This article deals with some aspects of the acquisition/learning
of a native speaker of Brazilian Portuguese, whose learning of French
language took place in the country where this language if originated,
France. Taking experiences directly in foreign context, this informer is
an example of the complicated process of acquisition/learning of a 
second language, related to linguistic and sociocultural aspects. Using descriptive analysis of the Portuguese (L1) and the French (L2), as well as the description of the difficulties of the informer, this study if guideline on the estimated ones considered by Contrastive Linguistics (LC). The contrast between linguistic and cultural systems is established as priority, having for purpose the observation the eventual deviates and blockades, classifying them in accordance with its characteristics. The aspects most excellent of difficulties lived deeply for the informer it's shown in the attempt to present to the professors and researchers of the area some real situations that surround the processes of acquisition and learning of a foreign language.

Keywords: Contrastive Linguistics; acquisition/learning of second language; descriptive and comparative analysis of the Brazilian Portuguese and French

Mas através das línguas vamos aprendendo um pouco de nós mesmos, de nossa ânsia gratuita, melancólica e vã.

Rubem Braga

\section{Preâmbulo}

Complexo e imperscrutável é o íntimo de um indivíduo face a uma língua estrangeira. As palavras que the chegam aos ouvidos, frases ditas a ele ou aquelas dirigidas a outrem, os textos e os sons que o circundam; tudo se configura como um mundo desconhecido e, não raro, temeroso e ameaçador; não obstante, também maravilhoso e envolvente.

Os sujeitos que se expõem, ou são expostos, ao contato com uma segunda língua, mesmo quando submetidos a situações previsíveis e recorrentes, respondem, até certo ponto, de maneira particular a essa experiência. Isso porque o aprendizado de uma língua estrangeira não se restringe simplesmente à aquisição do vocabulário, do sistema gramatical e das sutilezas da oralidade. Uma língua vai sendo apreendida aos poucos e num movimento contínuo, an fur et a mesure ${ }^{1}$ em que se

${ }^{1}$ Ao mesmo tempo e na mesma proporção. 
apreendem suas circunstâncias de uso, os costumes que lhe servem de fundo e o modus vivendi de algum grupo social que a fala.

Não seria exagerado dizer que o aprendizado de uma segunda língua esbarra na questão da identidade. Ao entrar em contato com um idioma diferente do materno, o indivíduo, forçosamente, "contrapõe-se" à sua língua nativa, assim como aos seus costumes, valores, tradições... E, no ato de comparar o que, de certo modo, é "seu" com o que, de certo modo, é do outro, tende-se a olhar o alheio com prevenção e com desconfiança, como se costuma fazer sempre que se está diante do diferente, do insólito, do não esperado. A outra língua, ao representar aquilo que se ignora, expõe a fragilidade de um ser frente a outros.

Se a comparação entre as línguas acontece com indivíduos que estudam um idioma estrangeiro em seus próprios países de origem, o que dizer daqueles que, sem nunca terem estudado antes, de modo formal, uma determinada língua, passam a conhecê-la num dos países onde ela é falada? Distante do país de origem e imersos em outra cultura, quais seriam as facilidades e/ou dificuldades do aprendizado da língua do outro?

Propomos-nos, neste trabalho, empreender uma análise de um caso particular: o de um falante nativo de português brasileiro cujo aprendizado de língua francesa se deu em um país onde tal língua é falada. Mais do que isso, até: onde essa língua teve origem: a França. Inserido diretamente no contexto estrangeiro, esse informante exemplifica o complexo processo de aprendizagem de uma segunda língua, no tocante a aspectos lingüísticos e socioculturais. Se, por um lado, o fato de estar completamente envolvido e absorvido pela língua estrangeira facilita a aprendizagem, já que não há outra alternativa que não seja se esforçar por falar e entender o que se fala, por outro lado, essa urgência de aprender e de se integrar pode vir a representar um entrave hercúleo para essa aprendizagem. A falta de contato com a língua materna também acaba por assumir um caráter de grande relevância na vida do sujeito aprendiz de uma língua estrangeira (LE), já que seu conhecimento de mundo se deu através dessa língua. A ausência da língua materna, incluída aqui como referencial do indivíduo aprendiz de LE, como parâmetro social, pode revestir-se de um caráter impeditivo e até de rejeição à língua estrangeira.

Estamos convencidos de que qualquer reflexão que traga esse tipo de discussão para o centro dos debates sobre descrição dos 
processos de ensino e aprendizagem de LE será pertinente. Ademais, pensamos que uma análise dos desvios e dificuldades dos aprendizes, além do contraste cuidadoso e sistemático entre duas línguas e culturas - neste caso, entre a variante brasileira de português, como língua materna do sujeito-aprendiz, e de francês, como língua estrangeira se mostra bastante útil, porque os professores e pesquisadores dedicados a essa temática, tendo conhecimento prévio de problemas reais que cercam os processos antes referidos, poderão não apenas detectar mais facilmente as dificuldades de seus alunos, como ainda estarão aptos a propor estratégias didático-pedagógicas especialmente voltadas para tais situações. Além disso, a partir do contraste e análise dos sistemas lingüísticos, professores e pesquisadores da área estarão habilitados a avaliar com propriedade materiais didáticos já existentes e elaborar outros, mais adequados a cada situação de ensino, partindo das características das línguas envolvidas, isto é, a língua materna e a língua objeto de estudo do sujeito aprendiz em questão.

O sujeito-informante, cuja experiência de aquisição e aprendizagem analisamos nessa ocasião, tem formação em comunicação social, com habilitação em jornalismo, pela Universidade Estadual de Londrina, esteve na França de 2003 até o final de 2006.

Em sua chegada àquele país, o sujeito-informante, de sexo feminino, 42 anos, tinha conhecimento de duas línguas estrangeiras: inglês e árabe. Na primeira delas, conseguia se comunicar com relativa facilidade, compreendia sem maiores problemas o que ouvia, lia muito bem, mas apresentava dificuldades para escrever de acordo com a norma padrão desse idioma. Na língua árabe, a qual o sujeitoinformante esteve exposta no ano de 1997, quando de um período de cerca de cinco meses na Universidade de Bagdá, no Iraque, ainda como estudante de jornalismo, não conseguia se expressar satisfatoriamente, mas entendia parcialmente o que ouvia, podendo ler e escrever, ainda que apresentasse claras lacunas de conhecimento.

Em relação à língua francesa, quando de sua chegada ao país, o sujeito-informante não tinha nenhum conhecimento de vulto, e o único contato com o referido idioma deu-se em 1972, quando cursava a $6^{a}$ série de ensino fundamental em um colégio estadual num município do interior do Paraná. Afora isso, seu conhecimento da língua francesa se restringia à compreensão de palavras cuja escrita se assemelha à língua portuguesa. O sujeito-informante, na fase inicial do 
processo de aprendizagem do francês, cerca de três meses após sua chegada, mostrou-se bastante motivado, mas, no período imediatamente posterior, ao perceber as complexidades lingüísticas do idioma em questão, sobretudo no que concerne à oralidade, foi se retraindo, apresentando, inclusive, algum recuo, o que poderia estar ligado principalmente às dificuldades de inserção sociocultural que experimentou.

Durante sua estada na França, estudou em escola freqüentada unicamente por estrangeiros adultos, na periferia de Paris. Criada e mantida por bénévoles, ${ }^{2}$ a escola, gratuita, com salas e infra-estrutura cedidas pela prefeitura e pela igreja católica, trabalha com os alunos individualmente, levando em conta suas necessidades e seu grau de instrução. Por lidar com pessoas de idades e características bastante diversificadas, a escola não prioriza um método específico, sendo escolhido aquele que mais se aplica a cada perfil. No curso, com duração de quatro horas diárias, cada bénévole se ocupa de, no máximo, dois alunos ao mesmo tempo.

Muitos estudantes dessa escola são provenientes de excolônias e protetorados franceses, como árabes magrebinos da Argélia, Tunísia e Marrocos, enquanto outros procedem da África subsaariana, como Mauritânia, Mali, Camarões, Senegal, Costa do Marfim, além de países da antiga Indochina, entre os quais Vietnã, Tailândia e Camboja, só para citar alguns. Nesses casos, quase sempre os alunos, notadamente das novas gerações, além de seus idiomas nativos, falam o francês, a língua do colonizador. Ainda que dominem a escrita, mas também havendo casos de pessoas que não foram alfabetizadas em seus países de origem, outros alunos, cujos idiomas são escritos com caracteres diferentes do latino - entre eles os oriundos de Sri Lanka (cingaleses), paquistaneses, chineses e russos - de modo geral, apresentam um nível de dificuldade maior do que os provenientes de países ocidentais, como os sul-americanos, e mesmo os portugueses, que também emigram para a França.

O sujeito-informante, durante o tempo que freqüentou o chamado Cours d'Alphabétisation de l'Association Renaissance de Culture, ${ }^{3}$ teve dois preceptores: um encarregado do ensino da língua propriamente

\footnotetext{
${ }^{2}$ Voluntários, a grande maioria aposentados, que mantêm atividades beneficentes. ${ }^{3}$ Curso de Alfabetização da Associação Renascença de Cultura.
} 
dito, e outro, das questões relativas à cultura e à civilização. O primeiro se orientou segundo as prioridades do aprendiz, que, dadas as características de sua formação profissional, optou por trabalhar logo de início com a produção e a versão de textos do português para o francês. O sujeito-informante trazia os textos já prontos para a sala de aula e, a partir deles, o professor ministrava as aulas, valendo-se de dicionários e de uma gramática, LE BLED, ${ }^{4}$ adotada na rede de ensino francesa. O segundo bénévole, que trabalhava com o aprendiz uma vez por semana, trazia para a sala de aula os principais jornais franceses do dia e apresentava assuntos relativos a política, artes e cultura, incluindo peculiaridades da sociedade local, como o caderno de obituário, denominado Carnet du Jour.

Decorrido o primeiro ano de estudos, confiante nos progressos que vinha acumulando, o sujeito-informante prestou exames de fluência de língua francesa, exigidos para entrada na Université Sorbonne - Paris 3. Admitido no último ano do curso Langues, Littératures et Civilisations Étrangères - Portugais (LLCE), ${ }^{5}$ período imediatamente anterior ao curso de mestrado local, o informante freqüentou um semestre e meio, voltando ao Brasil antes do término do ano letivo.

\section{Desenvolvimento}

\subsection{Fundamentação teórica}

Já no avant-propos, ${ }^{6}$ apresentamos, em linhas gerais, o objeto deste estudo e o contexto no qual o processo de aquisição de LE do sujeito-informante se deu. Neste ponto do trabalho, debruçar-nosemos de forma mais contundente sobre o assunto, apoiando-nos sobre o referencial teórico que tornará possível a sustentação de nossa proposição, ao mesmo tempo em que iremos pontuando, no decorrer do texto, os principais problemas de aprendizado vivenciados pelo sujeito-informante.

Tomaremos como base a análise descritiva do português (L1) e do francês (L2), e a descrição das dificuldades do sujeito-

${ }^{4}$ LE BLED: Orthographe, Grammaire, Conjugaison

${ }^{5}$ Línguas, Literaturas e Civilização Estrangeiras (LLCE) - Português.

${ }^{6}$ Preâmbulo. 
informante, orientando-nos sobre os pressupostos da Lingüística Contrastiva (LC). Estabeleceremos como prioridade o contraste entre sistemas lingüísticos e culturas, focalizando o processo de aquisição do francês pelo falante adulto da variante brasileira do português a quem aludimos, com a finalidade de observar os eventuais desvios e bloqueios, classificando-os de acordo com suas características, sempre amparados na fundamentação teórica pela qual optamos, no intuito de entender as situações de ordem lingüística e cultural experimentadas por ele.

Contrastar sistemas lingüísticos, determinar as facilidades e dificuldades entre duas línguas, analisar a gramática pessoal e entender a interlíngua como um sistema lingüístico em construção estão, grosso modo, entre os interesses da LC. Durão (1999) reitera que a LC se concentra particularmente nos efeitos que as diferenças e eventuais semelhanças entre a estrutura de uma língua materna (LM) e de uma língua estrangeira (LE) podem vir a causar no aprendizado de uma LE. Os estudos contrastivos se prestam, sobretudo, a auxiliar no planejamento bem elaborado de cursos de línguas estrangeiras e na proposição de estratégias funcionais de atendimento por parte dos professores desse campo.

Conforme Durão (1999), em LC pode-se falar principalmente em dois modelos de análise: o modelo de Análise Contrastiva (AC) e o modelo de Análise de Erros (AE), assim como na Análise da Interlíngua. O primeiro deles é de cunho estruturalista comportamental, baseado em preceitos behavioristas, caracterizados pelo binômio estímulo-resposta. O erro, sob o viés da AC, é visto como algo condenável, devendo ser evitado a todo custo. O AC enxerga no erro a interferência ou transposição de certos elementos de ordem fonética, morfológica, sintática, semântica, pragmática ou cultural da língua materna para a língua estrangeira. Sendo os erros decorrentes da interferência, conforme postula este modelo, seria possível, considerando seus pressupostos, prevê-los e contorná-los, algo que posteriormente se matizou, como se comentará.

A principal crítica que se faz à $\mathrm{AC}$ diz respeito justamente à proposta de que é possível predizer e pontuar as falhas que os aprendizes irão cometer. Verificou-se, a partir de estudos empíricos, que muitos erros previstos em determinadas situações não eram passíveis de ser evitados sem contar com outros tantos tipos de erros que, mesmo sem serem anteriormente cogitados, surgiam, colocando na berlinda a 
própria postulação da teoria. Isso porque, como a língua, a pessoa é um organismo vivo e, nesse sentido, nem um nem outro podem ser encaixados em concepções estáticas. Ao contrário: o normal é que tanto o indivíduo quanto a língua estejam todo o tempo em constante transformação. A aquisição de uma LE, sob essa ótica, é um processo particular que não se resigna a fórmulas prontas e acabadas.

Tudo isso não significa dizer, absolutamente, que o contraste entre os sistemas lingüísticos não deva ser realizado. Alguns autores, como Fries (apud LADO, 1971) argumentam que podem surgir importantes contribuições da contraposição, notadamente sobre os recursos didáticos: "Os materiais mais eficazes são os baseados numa descrição científica da língua a ser aprendida, comparada cuidadosamente com uma descrição paralela da língua nativa do aprendiz". De acordo com Lado (1971), ao determinar as diferenças e semelhanças entre dois sistemas lingüísticos, é possível construir uma gramática contrastiva que estabeleça as correspondências dos diferentes níveis gramaticais de L1 e L2.

A análise contrastiva é um dos recursos que a LC lança mão para compreender o processo que acompanha a aquisição de uma segunda língua na mente humana. Entretanto, como já foi colocado, face às limitações que se constataram no próprio seio da $\mathrm{AC}$, propôsse outro modelo de análise: o AE. Essa nova concepção assumiu outro estatuto, notadamente após o desenvolvimento de grande parte dos trabalhos de Chomsky, sobre aquisição das línguas maternas, a partir de 1965. Os desvios, para esse autor, passaram a ser interpretados como erros de performance, causados, por exemplo, por cansaço ou desatenção, e erros de competência, classificados em função do desconhecimento das regras do sistema da língua estrangeira.

Corder, em 1967, orientando-se pela vertente proposta por Chomsky (ainda que o propósito deste, diferentemente dos de Corder, tenham se centrado no desvendamento da aquisição das línguas maternas), verificou que os erros se constituem em mecanismos substanciais por meio dos quais se tem acesso à gramática interna do aprendiz, ou seja, para Corder, a análise de erros fornece, pois, subsídios para que se possa conhecer o andamento da aquisição de uma língua estrangeira por parte de um aprendiz, oferecendo índices da progressão do conhecimento daquela língua. Segundo Durão (2007), o ineditismo dessa concepção ganhou mais fôlego após Selinker ter publicado, em 
1972, o artigo Interlanguage, e em conseqüência, ter desencadeado o que veio a ser conhecido como Análise de Interlíngua. Nele, o autor propôs o conceito de interlíngua, uma espécie de sistema lingüístico intermediário que contém elementos da LM e da LE. Selinker (1972) percebeu que a interlíngua vai se transformando na mesma proporção em que se dá o aprimoramento do conhecimento da LE. Como um fenômeno transitório, a interlíngua e sua gramática particular revelam os diferentes estágios do processo de aprendizagem de LE do indivíduo. A análise da interlíngua, portanto, pode, nesse contexto, avaliar como o aluno aprende e o que ele já internalizou até aquele momento. Os "erros" ou, melhor dizendo, as inadequações presentes nas produções lingüísticas dos aprendizes demonstram, assim, a quantas anda o progresso lingüístico dos alunos na aprendizagem de uma LE, ainda que, como ressaltou Durão (2007), estes não constituam a interlíngua, sendo apenas parte dela.

As inadequações dos aprendizes são, portanto, frutos tanto da interferência da LM quanto das metodologias empregadas e da própria LE, entre muitos outros aspectos. As dificuldades encontradas são classificadas, em um primeiro momento, de acordo com as semelhanças e diferenças entre a língua nativa e a língua alvo. Conforme Lado (1971), os padrões de dificuldade de L2 em relação à L1 referemse

às palavras que são (1) semelhantes em forma e em sentido; (2) semelhantes em forma mas diferentes em sentido, (3) semelhantes em sentido mas diferentes em forma, (4) diferentes em forma e em sentido, (5) diferentes no seu tipo de construção, (6) semelhantes no sentido primário mas diferentes na conotação, e (7) semelhantes em sentido mas com restrições na distribuição geográfica.

Como alguns desses grupos se superpõem, fazendo com que algumas palavras se enquadrem em mais de um grupo, as dificuldades variarão um pouco. Não obstante, poderemos prever um nível geral de dificuldade com base nesses agrupamentos e classificaremos cada grupo em um dos três níveis de dificuldade: (1) fácil, (2) normal, (3) difícil.

Aplicando a proposta de Lado (1971), podem-se classificar como palavras que apresentam semelhança na grafia e no sentido, iguais às que destacamos: plante, musique, famille, enquanto que outras são 
absolutamente próximas, apesar de sua pronúncia ser diferente: café [kafE], canapé [kanapE], pronunciadas com som aberto em português, e café [kafe], canapé [kanape], com som fechado em francês.

Os heterogenéricos, palavras que muitas vezes têm grafia e significado semelhantes nas duas línguas, diferem, por sua vez, no tocante ao gênero, podendo, por isso, vir a acarretar problemas de construção quando não identificados pelos alunos. Em francês temos, por exemplo: la tomate, la période, la vidéo, la minute, le compte, le passage; frente ao português: o tomate, o período, o vídeo, o minuto, a conta, a passagem.

No grupo considerado difícil, podemos situar, seguindo as propostas de Lado (1971), os falsos cognatos, ou falsos amigos, como são mais conhecidos, palavras semelhantes na forma, mas com sentidos diferentes. Citamos alguns exemplos de palavras em francês e português, analisadas aqui sob os três aspectos propostos pelo autor: forma, sentido e distribuição.

\section{"FRACAS"}

\section{Forma}

Fracas. [frakA], n.m.

1. Bruit violent, (locution) - avec perte et fracas: brutalement.

\section{Sentido}

O substantivo significa barulho violento, estrondo. Na locução "com perdas e estrondo", temos o sentido de estrondosamente, brutalmente.

\section{Distribuição}

A palavra é encontrada apenas com o sentido de som estrondoso e violento. No sentido figurado, é utilizada como uma ação intempestiva, produzida com estardalhaço.

A palavra fracas faz lembrar, em português, o substantivo fracasso, exposto a seguir:

\section{"FRACASSO"}

\section{Forma}

Fracasso. [fracasu], s.m.

1. Ato de fracassar; malogro. 2. Fragor, estrépito, barulho.

\section{Sentido}

A palavra equivale à derrocada, a uma ação que não foi concluída a contento. 


\section{Distribuição}

Empregada em referência a determinado ato que não teve resultado positivo, a palavra fracasso lembra sempre algo que terminou errado, uma ação malograda, sem êxito, como no exemplo: "O filme foi um fracasso de bilheteria". Nesse caso, deduz-se que o público não acorreu aos cinemas, que o filme não caiu no agrado da platéia. Também nesse outro caso, "fracasso escolar", o termo implica idéia negativa. Pensa-se que o aluno não reuniu resultados satisfatórios, que sofreu reprovações e teve mau desempenho.

Apesar de a palavra fracasso, em português, também ter o sentido de ruído estrondoso, é pouco empregada como tal. O aprendiz brasileiro de francês, ao ouvir o vocábulo francês fracas, vai se remeter à palavra em português, interpretando-o erroneamente.

Outro falso cognato causa particular embaraço. Vejamos:

\section{"STUPRE"}

\section{Forma}

Stupre. [stypr] n.m.

1. Débauche bonteuse, bumiliante - luxure.

\section{Sentido}

O substantivo, em francês, tem o sentido de conduta vergonhosa, humilhante - luxúria.

\section{Distribuição}

O vocábulo diz respeito a comportamento reprovável, como nesse exemplo: "l'atmosphère invite aux voluptés sommaires, aux jeux, aux stupres" (André Gide). A frase pode ser entendida como: "a atmosfera convida às volúpias sumárias, aos jogos, às devassidões" - (André Gide). Entendemos, pois, que stupre está relacionado à devassidão, libertinagem, desregramento. Em francês, o vocábulo stupre, de uso literário e pouco empregado atualmente, pela semelhança na forma escrita remete, em português, a estupro. Ocorre que, em francês, estupro é viol, ou seja: "acte par laquel une personne en force une autre à avoir de relations sexuelles avec elle, par violence" - "ato pelo qual uma pessoa força uma outra a manter relações sexuais com ela por meio da violência".

\section{"ESTUPRO"}

\section{Forma}

Estupro. [istupru] s.m

1. Ato de coagir uma pessoa, com violência ou sob ameaças, à prática sexual. 


\section{Sentido}

Em português não há outro sentido se não o de coito forçado, ato sexual praticado sob coação.

\section{Distribuição}

Aparece apenas em situação que diz respeito à violência sexual, em que uma pessoa é obrigada, pela força física ou psicológica, a manter relações sexuais. A palavra tem uma carga de imagem violenta, é sempre entendida dentro do contexto de violência, em que há oposição entre força e fragilidade.

\section{"HASARD"}

\section{Forma}

Hasard. ['azaR] n.m.

1. Jeu de dés en usage au Moyen Âge; coup heureux à ce jeu (le six). 2- Jeu de hasard, où le calcul, l'habilité n'ont aucune part (dés, roulette, baccara, loterie).

2. Risque, circonstance périlleuse. - danger. Être, mettre au hasard, en hasard: s'exposer, exposer à un risque, un péril.- hasarder. Les hasards de la guerre.- aléa, incertitude. 2. Cas, événement fortuit; inexplicable. Quel hasard!- coïncidence. C'est un vrai, un pur hasard, rien n'était calculé, prémédité. Un curieux hasard. Heureux hasard.- aubaine, chance, veine; occasion. Hasard malheureux.- accident, déveine, malchance. Coup de hasard: événement fortuit.

\section{Sentido}

Um dos sentidos refere-se a um jogo de dados conhecido desde a Idade Média. A palavra aparece ainda como jogo de azar, em que o cálculo e a habilidade não contam. São citados alguns exemplos de jogos: dados, roleta, bacará e loteria.

Outro sentido encontrado é o de risco, de circunstância perigosa. Temos também hasard como acaso, aleatoriedade, incerteza, acontecimento fortuito, inexplicável, coincidência, providência feliz, ocasião, acidente, má sorte.

\section{Distribuição}

Quanto à distribuição, a palavra, em francês, é preferencialmente utilizada como acaso, causalidade: "Tout ce qui existe est fruit du hasard et de la necessite"" (Monod). (Tudo o que existe é fruto do acaso e da necessidade). A palavra hasard vem como capricho do destino, da fortuna, da fatalidade e da sorte: "Le souci de ne rien laisser an hasard" (Mauriac). (A preocupação de não deixar nada passar ao acaso). 
Encontramos hasard nas locuções "ao acaso" e "por acaso": "Tl est absurde de chercher un puits, au hasard, sur le juste et l'injuste" (Saint-Exupéry). (É absurdo pensar em procurar um poço ao acaso, a torto e a direito); "Rencontrer - ou tomber - sur quelqu'un par hasard", (Encontrar alguém por acaso - ou, como se diz comumente, trombar, dar de cara com alguém por acaso).

Mesmo quando a palavra hasard refere-se a jogo, ela vem com esse caráter de casualidade, de algo que pode ou não acontecer, e isso pode ser um acontecimento positivo ou não. "Un coup de dés jamais n'abolira le hasard" (Mallarmé). (Um jogo de dados nunca descartará o acaso).

\section{"AZAR"}

\section{Forma}

Azar. [Do ar. Az-zahar ou az-zahr, jogo de dados] s. m.

1. Má sorte; fortuna adversa; caiporismo. 2. Revés, fatalidade, desgraça, infortúnio. 3. Casualidade, acaso.

\section{Sentido}

O principal sentido do substantivo 'azar', em português, é o de má sorte, de adversidade e infortúnio. O sentido de casualidade vem em terceiro lugar.

\section{Distribuição}

Em português, a palavra 'azar', ainda que também tenha o sentido de acaso, é sempre utilizada com conotação de adversidade e infortúnio. Dificilmente se pensará numa frase em que esse substantivo não tenha essa carga de conotação de "sorte madrasta". No exemplo: "E, se por azar, en o encontrar na rua?", podemos pensar, sim, no fator de causalidade - o de encontrar (ou não) uma pessoa - entretanto, a conotação aí é negativa, ou seja, o sujeito que pode (ou não) ser encontrado na rua, parece ser alguém indesejável. O falante de português vai, assim, optar pela palavra "acaso", muito mais adequada à situação: "E se, por acaso, en o encontrar na rua?".

\section{"POURTANT"}

\section{Forma}

Pourtant. [purtã]

1. Adverbe marquant l'opposition entre deux choses liées, deux aspects contradictoires d'une même chose. - cependant, mais, néanmoins, toutefois. 


\section{Sentido}

Em francês, pourtant é advérbio que marca a oposição entre dois termos ligados, ou dois aspectos contraditórios de uma mesma coisa. - mas, entretanto, porém, todavia.

\section{Distribuição:}

Como advérbio de oposição, a palavra pourtant é assim utilizada pelos falantes de francês: "Oh! argent quej'ai tant mépris [...] tu as pourtant ton mérite" (Chateaubriand). (Oh! dinheiro que eu tanto desprezei [...] você tem, entretanto, seu mérito); "Et pourtant elle tourne [la Terre]" (Galileu Galilei). (Todavia, ela se move) - frase dita por Galileu após a retratação; "triste, découragée, souriante pourtant" (Proust) - (triste, desencorajada, mas sorridente).

\section{"PORTANTO"}

\section{Forma}

Portanto: Conjunção conclusiva - introduz uma oração coordenada que mantém a conclusão de um raciocínio; logo, por conseguinte, conseqüentemente, por isso, desse modo, assim sendo, pois.

\section{Sentido}

A conjunção "portanto" está ligada à idéia de conseqüência conclusiva de um argumento qualquer.

\section{Distribuição}

Vemos no exemplo a distribuição da conjunção 'portanto' na língua portuguesa: "O time não marcou nenbum gol, portanto, está fora do campeonato".

Vejamos na tabela a seguir um resumo da análise de falsos cognatos aqui analisados: LF se refere à Língua Francesa e LP à Língua Portuguesa. 


\begin{tabular}{|c|c|c|c|}
\hline PALAVRA & FORMA & SENTIDO & DISTRIBUIÇÃO \\
\hline HASARD/AZAR & $\begin{array}{c}\text { Mesmo } \\
\text { apresentando uma } \\
\text { pronúncia próxima, } \\
\text { não possuem a } \\
\text { mesma forma }\end{array}$ & $\begin{array}{l}\text { Em LF há vários } \\
\text { sentidos: 'um jogo } \\
\text { de dados da Idade } \\
\text { Média',' 'risco', } \\
\text { 'acaso'. Em LP } \\
\text { significa 'má sorte' } \\
\text { e 'casualidade'. }\end{array}$ & $\begin{array}{l}\mathrm{Na} \text { LF é mais usada como } \\
\text { 'acaso', e em LP, mesmo } \\
\text { apresentando um sentido } \\
\text { de 'acaso' é mais usado } \\
\text { como 'adversidade' e } \\
\text { 'infortúnio'. }\end{array}$ \\
\hline POURTANT/PORTANTO & $\begin{array}{l}\text { Possuem forma e } \\
\text { pronúncia } \\
\text { próximas. }\end{array}$ & $\begin{array}{c}\text { Em LF marca } \\
\text { oposição entre } \\
\text { dois termos, tem } \\
\text { sentido de } \\
\text { 'entretanto'; em LP } \\
\text { está ligada à idéia } \\
\text { de 'conseqüência.' }\end{array}$ & $\begin{array}{l}\text { Enquanto o termo da LF } \\
\text { se distribui como } \\
\text { 'advérbio de oposição', o } \\
\text { termo da LP se distribui } \\
\text { como 'conjunção } \\
\text { conclusiva.' }\end{array}$ \\
\hline STUPRE/ESTUPRO & $\begin{array}{l}\text { Apresentam forma } \\
\text { semelhante, mas } \\
\text { têm sentidos } \\
\text { opostos. }\end{array}$ & $\begin{array}{c}\text { Em LF tem } \\
\text { sentido de } \\
\text { 'conduta } \\
\text { vergonhosa, } \\
\text { humilhante, ligada } \\
\text { à volúpia, luxúria'; } \\
\text { em LP significa' } \\
\text { 'ato sexual } \\
\text { forçado, violento.' }\end{array}$ & $\begin{array}{c}\text { Distribuem-se } \\
\text { diferentemente: em LF } \\
\text { está ligado à 'devassidão, } \\
\text { libertinagem, } \\
\text { desregramento'; em LP, } \\
\text { aparece como 'coito } \\
\text { praticado sob coação e } \\
\text { ameaças.' }\end{array}$ \\
\hline FRACAS/FRACASSO & $\begin{array}{l}\text { Apresentam forma } \\
\text { e pronúncia } \\
\text { próximas. }\end{array}$ & $\begin{array}{c}\text { Em LF tem } \\
\text { sentido de 'barulho } \\
\text { violento, } \\
\text { estrondo', e em LP } \\
\text { corresponde a } \\
\text { 'malogro, } \\
\text { derrocada', e } \\
\text { também a 'fragor, } \\
\text { barulho.' }\end{array}$ & $\begin{array}{c}\text { Distribuem-se de maneira } \\
\text { distinta. Em LF aparece } \\
\text { como 'som estrondoso, } \\
\text { ação intempestiva'; já em } \\
\text { LP, apesar de ter também } \\
\text { sentido de 'barulho', } \\
\text { corresponde sempre a } \\
\text { 'ação malograda, sem } \\
\text { êxito.' }\end{array}$ \\
\hline
\end{tabular}

\subsection{Análise de dados}

O sujeito-informante relatou ter encontrado alguns problemas no emprego de termos e expressões correntes na língua francesa. Passemos, pois, à análise dos principais exemplos que ilustram as dificuldades de aprendizado sentidas por ele no que se refere aos dois sistemas lingüísticos e às duas culturas em tela.

Tomemos de início a expressão francesa ce n'est pas grave, ou, como se diz coloquialmente, c'est pas grave, omitindo-se aí a partícula de negação ne. A frase pode ser traduzida, ao português, como "não tem problema". Esse enunciado, em português, é quase uma convenção, sendo usado a todo o momento em situações corriqueiras do dia-adia, em resposta, por exemplo, a um pedido de desculpas por um esbarrão, ou quando se entorna um copo de vinho na toalha da mesa. Dizer, em português, "não tem problema", não acarreta nem ao falante e nem ao ouvinte maiores elucubrações. Já em francês, por outro lado, 
na expressão ce n'est pas grave, o que fica marcado para o aprendiz é a palavra "grave", escrita da mesma maneira nas duas línguas. Seu significado, para um falante de português, causa forte impressão, pois o termo remete a algo sério, pesado, de conseqüências danosas, nefastas, como nas seguintes frases: "o acidente foi grave", ou, "o estado do paciente é grave". Um aprendiz brasileiro de francês, ao ouvir essa expressão francesa, tende a concentrar sua atenção na palavra grave, e a fazer o decalque da expressão ao pé da letra: "não é grave". Ora, a frase, dita assim, adquire um outro formato, bem mais carregado. Subentende-se que havia alguma coisa que poderia ser preocupante e que, por fim, se configurou em algo nada desastroso. Mas, dizer que alguma coisa "não é grave" não ameniza, nem redime de todo o ocorrido em questão. A expressão continua com seu ar circunspecto, funesto, "grave", em que pese o trocadilho.

Outro exemplo é a locução tout à fait, que corresponde, em português aos advérbios "completamente", "inteiramente", "totalmente", "exatamente". Costuma ser dita em resposta assertiva ao teor de uma conversação, em concordância sem nenhuma ressalva com o sujeito que fala. Enquanto na escrita fica clara a separação de cada uma das palavras - tout + à + fait - ao ser dita, a locução é pronunciada assim: [tutafe]. A estrutura fônica da locução francesa faz lembrar em português a expressão tudo a ver [tuduave], utilizada como resposta a um enunciado que tenha relação com o assunto discutido.

Comparando a transcrição fonológica das duas expressões, podemos observar a ocorrência de um fenômeno que em fonologia é chamado de teste de comutação: a troca de um som por outro. Vejamos essa ocorrência lingüística nas locuções abaixo.

Tout à fait

A consoante / $\mathrm{t}$ / é oclusiva surda

A consoante /f/ é fricativa surda

\section{Tudo a ver}

/d/ é oclusiva sonora

/v/ é fricativa sonora

Segundo Cagliari (1989), é sabido que existe dificuldade em diferenciar os sons surdos dos sonoros. A troca de um fonema por outro, não obstante, costuma provocar equívocos, tanto na fala quanto na escrita. Nos exemplos citados, o aprendiz tende a buscar 
imediatamente na língua materna o correspondente à locução em francês. Lado (1971) explica que os aprendizes tendem a fazer transferências de seu sistema lingüístico nativo no aprendizado da língua estrangeira. De acordo com esse autor, a juntura e a fronteira entre as palavras constituem-se em problema de importância para o aluno de língua estrangeira, que nem sempre está apto para identificar de pronto as partes constituintes do enunciado, e, por conseguinte, tende a distorcer o seu sentido lexical.

Ao ouvir a locução tout à fait - [tutafe], o aluno pode entender que foi dito tudo a ver - [tuduave]. Temos aí a troca de dois fonemas: /t/ por /d/; /f/ por /v/. Ao fazer a comutação o aprendiz chega a um entendimento que não corresponde ao sentido original que a referida expressão em francês.

Contudo, se pensarmos que a locução tout à fait é usada quando o sujeito concorda incondicionalmente com a pessoa que fala, não é de todo errôneo pensar que a expressão tudo a ver pode também significar completamente, inteiramente. Quando se diz que um enunciado tem tudo a ver com o que se está discutindo é porque se acata como válida a idéia proposta pelo sujeito que fala, o que, de certa forma, equivale ao significado existente em tout à fait.

Peguemos agora o vocábulo culotte [kylot] n.f. 1- Vêtement masculin de dessus qui couvre de la ceinture aux genoux (d'abord serré aux genoux) et dont la partie inférieure est divisée en deux éléments habillant chacun une cuisse (opposé à pantalon). Les sans-culottes (le révolutionnaires - les aristocrates portaient la culotte). Vêtement de forme analogue porté par les enfants et les sportifs: porter des culottes courtes - short, bermuda. Fig. Trembler dans sa culotte: avoir très peur. C'est elle qui porte la culotte: c'est elle qui commande son mari - "Dans le ménage, c'était le mari qui portait les jupes et la femme les culottes" (Proust). Attraper quelqu'un par le fond de la culotte; baisser culotte. se soumettre, avouer. Vulg. N'avoir rien dans la culotte: être impuissant, lâche (c'est le même que n'avoir pas des conilles). 2-Sous-vêtement féminin qui couvre le bas du tronc, avec deux ouvertures pour les jambes- slip; culotte de bains (hommes et enfants). 3- Boucherie. Partie de la cuisse du boeuf, de l'échine au filet.

Numa tradução livre, são esses os significados que o dicionário francês consultado traz para o substantivo feminino culotte: 1- Roupa de baixo masculina que cobre desde a cintura até os joelhos 
(originalmente era presa aos joelhos), cuja parte inferior é dividida em duas partes, cada uma vestindo uma coxa (por oposição à calça comprida). Os sans-culottes (os revolucionários [chamados assim durante a Revolução Francesa], pois os aristocratas usavam calças). Roupa análoga usada por crianças e esportistas: usar calças curtas - short, bermuda. Fig. Tremer nas calcas (ou mijar nas calcas, como se diz vulgarmente em português): ter muito medo; agarrar alguém pelo fundo das calças; baixar as calças: se submeter, confessar. Chulo. Não ter nada dentro das calças: ser impotente, frouxo - (o mesmo que não ter collhões). Diz-se também da mulher que manda na casa: enquanto ele veste saia ela usa calças. 2Roupa íntima feminina que cobre o baixo ventre, com duas aberturas para as pernas - slip; calção de banho. 3- Açougue. Parte da coxa do boi que vai da região das costas ao filé.

Ao ouvir o vocábulo culotte, o aluno brasileiro de francês tende a procurar em seu repertório nativo algo correspondente e a fazer analogia com o substantivo masculino culote, que, em português, adquiriu outros sentidos que não exatamente os mesmos propostos na língua francesa. Entre os significados do português, o mais conhecido é aquele que liga culote à "celulite e gordura localizada nas coxas e alto dos quadris". Além desse, constam outros significados nos dicionários em português: "Calça comprida, bem larga nos quadris e justa abaixo do joelho, usada para montar a cavalo. Parte posterior reforçada de um projétil ou de um estojo de um cartucho. (Encontram-se no culote do estojo o alojamento da cápsula ou estopilha e a virola pela qual o estojo é extraído do cano)".

Dada a similaridade dos termos - culotte e culote - tanto na forma oral, quanto na escrita, o aprendiz pode ser induzido a crer que em ambas as línguas têm o mesmo sentido, ou melhor, que o nome em francês também quer dizer gordura localizada na região dos quadris. Mesmo após conhecer os significados de culotte, o aluno considera um tanto improvável que essa mesma palavra se refira tanto a cueca quanto a calcinha. Por existir na língua portuguesa uma designação específica para essas peças íntimas do homem e da mulher, o aprendiz pode ser levado a pensar no vocábulo com certo constrangimento, a dirigir-lhe um olhar enviesado, como se tivesse encontrado na língua francesa uma falha que o coloca em situação, digamos, desconfortável.

Vejamos, agora, a palavra composta rendez-vous [randevu], que aparece assim no dicionário francês: "n.m. Rencontre convenue 
entre des personnes. Lieu de rencontre." Isso pode ser entendido como: "subs. masc. Encontro marcado entre pessoas. Lugar de encontro". O substantivo, na verdade, é o imperativo do verbo rendre na segunda pessoa do plural (rendez-vous à tel endroit - dirija-se, encaminhe-se a tal lugar). Essa palavra foi incorporada ao léxico do português, sendo escrita exatamente como na língua francesa. "Rendez-vous: ponto de encontro; local escolhido para entrevista; conversa, encontro marcado, combinado de antemão". Percebemos que em português o termo, mesmo mantendo os sentidos originais do francês, recai mais particularmente sobre o local do que sobre o encontro em si. No português o vocábulo rendez-vous abrasileirou-se, recategorizou-se, sendo muito mais conhecido por randevu, existindo também variações para randivu. Exemplo de regionalismo, a palavra se popularizou sobremaneira nas cidades interioranas do Nordeste, e significa "casa de prostituição, local de encontros libidinosos, prostíbulo, bordel”. A palavra é empregada, particularmente, no sudoeste da Bahia, nos vilarejos dos arredores do rio Gavião, sudoeste daquele Estado, como sinônimo de confusão, entrevero, balbúrdia, bate-boca, mas sempre tendo mulheres como pivô.

Essa recategorização da palavra pode ter-se dado pela influência francesa durante o período colonial do Brasil, especialmente no Rio de Janeiro e em São Luiz, locais que estiveram sob o domínio dos franceses. Constam da história oficial pelo menos duas investidas principais, a primeira em 1555, quando 600 franceses liderados por Nicolas Durand de Villegaignon dominaram o Rio de Janeiro com o intuito de fixar ali uma colônia (a França Antártica). Depois de serem expulsos pelos portugueses em 1567, os franceses fizeram ainda uma segunda tentativa, dessa vez no Maranhão, em 1612, quando o aventureiro Daniel de la Touche, senhor de uma região chamada La Ravardière, na França, à frente de 500 homens, fundou na costa maranhense a cidade de Saint Louis (manteve-se o nome, mas aportuguesou-se para São Luiz), capital daquela que seria a França Equinocial, projeto que durou apenas três anos. Em 1615, rechaçados pelos portugueses, os franceses debandaram, contornando a costa norte da Amazônia, instalando-se na região onde hoje se encontra a Guiana Francesa, vizinha do Brasil.

Logicamente, nessas tentativas de colonização do Brasil, os franceses acabaram deixando para trás mais do que apenas fortalezas, 
faróis e outras obras arquitetônicas nas regiões onde estiveram presentes. A língua francesa, talvez mais do que qualquer um desses itens, manteve um convívio com o português do Brasil colônia, com os povos indígenas e africanos, numa mistura deveras inusitada e, ainda hoje, pouco estudada.

E, para reforçar ainda mais a temática da presença francesa no Brasil, "importaram-se" posteriormente os costumes da belle époque, que teve seu apogeu em fins do século XIX. Desse período até meados do século XX, quando a língua e cultura americana começaram a se impor, o francês era tido como símbolo de refinamento, daí a ser ensinado nos colégios freqüentados pela elite brasileira. $\mathrm{Na}$ época, afluíam para o Brasil grandes expoentes franceses da música e das artes em geral, de todos os gêneros e especialmente dançarinas de cancan (famoso espetáculo de dança encenado na casa de shows Moulin Rouge, no bairro parisiense de Montmartre, em 1900). Atrizes, cantoras e dançarinas aportavam por aqui desejosas de fazer fortuna nos trópicos (em 1935, quando da visita do antropólogo franco-belga Claude LéviStrauss, foram eles chamados de Tristes Trópicos, título de seu célebre livro). Nesse contexto, existiam artistas francesas que aceitavam encontrar-se com os admiradores longe de seus camarins, e, para tanto, marcavam os tais rendez-vous. Os encontros, no imaginário popular, acabaram tomando outros ares, remetendo a entrevistas fortuitas e pouco ortodoxas, e as artistas francesas foram associadas a mulheres de comportamento reprovável. De rendez-vous para randevu foi um pulo. Numa mostra de criatividade e mobilidade da língua, a palavra francesa, incorporada ao léxico brasileiro, passou a ser utilizada, por extensão, como sinônimo de zona do baixo meretrício.

Passemos, nesse ponto, à comparação de alguns aspectos das duas culturas. Segundo a argumentação de Lado (1971), destacamos o fato de que os indivíduos de um mesmo grupo ou povo costumam, na maioria das vezes, exacerbar sua própria cultura e olhar com desconfiança e, em alguns casos, até mesmo com reprovação para a alheia. Mas, apesar de empregada cotidianamente, poucos podem definir com objetividade o sentido exato da palavra cultura. Antes de pontuar aspectos dessa ou daquela cultura é preciso, insiste Lado (1971), ser capazes de "descrever as situações em que fazemos o que fazemos". As culturas, continua ele, são sistemas estruturados de comportamento padronizado. Ainda, insiste o autor, as atitudes individuais dos membros 
de uma cultura nunca são as mesmas. Cada ato é único, por mais que seja exaustivamente repetido. O que Lado (1971) quer dizer é que as manifestações de uma cultura, mesmo sendo mudadas aqui e ali pelos membros de uma determinada comunidade sociocultural, mesmo tendo "elementos substituíveis como ator, ato, objetos, cenário, tempo, modo, fim, etc.", continuam as mesmas e, ainda que assumam propriedades diferentes, exprimem o que é comum ao grupo.

Os hábitos alimentares, como argumentou Lado (1971), são bons campos de observação das unidades de comportamento padronizado que constituem os esquemas de cada cultura, considerando que eles possuem forma, sentido e distribuição específicos. O sujeitoinformante relatou ter tido particular dificuldade em assimilar aquilo que lhe pareceu diferente daquilo que considerava serem seus hábitos alimentares, e a cada instante se punha a estabelecer comparações da própria cultura com a estrangeira. Nesse ponto, ressaltamos nossa preocupação em pretender evitar o erro grosseiro de generalizar manifestações culturais, quaisquer que elas sejam. Reiteramos que este estudo apresenta um caso particular, de tão somente um indivíduo, e que o olhar dele, bem como o de todas as pessoas, como é evidente, está impregnado de suas próprias vivências, priorizando este ou aquele detalhe, conforme suas convicções e critérios pessoais. Esse olhar pode, certamente, divergir do de outra pessoa que tivesse vivido experiências similares, no mesmo tempo e lugar, situadas em outro espaço temporal. De todos os modos, estamos convictos de que, mesmo em se tratando de um relato colhido a partir de um único informante, esta análise vem a acrescentar novas luzes sobre aspectos lingüísticos derivados do contato sistemático entre culturas diferentes, tomadas, claro, como dois grandes blocos.

Um almoço típico em casa de uma família francesa (dados coletados numa residência num subúrbio de Paris) começa por volta do meio dia. Mesmo durante a semana, quando as pessoas trabalham e não dispõem de muito tempo para estarem à mesa, os franceses costumam fazer da hora do almoço um acontecimento que, aos olhos do sujeito-informante deste estudo, pareceu sempre especial. Enquanto a comida ainda é preparada, as pessoas se servem de apéritifs (aperitivos: nozes, patês e amendoins salgados, por exemplo), acompanhados por vinhos. Costuma-se tomar um drinque preparado com vinho branco gelado e licor de cassis (uma fruta vermelha, que lembra a amora). Vez 
por outra os vinhos franceses dão lugar ao vinho do Porto nesse momento da refeição. A disposição temporal dos pratos servidos é seguida à risca, com a entrada, vindo em primeiro lugar. Em geral serve-se um desses pratos: fatias de jambon (presunto), rodelas de abacate, rodelinhas de rabanetes crus, coquilles saint-jacques (um molusco marinho muito apreciado), fatias de salmão, quiche (torta salgada), cenoura ralada, fatias de melão, ou ainda taboulé (prato de origem libanesa, preparado com sêmola de trigo crua, menta, salsinha e temperos). Bastante popular é a ratatouille, prato provençal feito à base de legumes (berinjelas, tomates, abobrinhas), frio, oferecido como entrada. A bebida que acompanha os aperitivos continua na mesa junto com a entrada.

Não se costuma tomar refrigerante durante as refeições; somente vinho e água. $\mathrm{Na}$ mesa nunca faltam a baguette e le beurre (pão e manteiga). Terminada a entrada, passam-se pedacinhos de pão no prato, limpando totalmente o que restou dos molhos. O pão, notese, é usado fazendo as vezes de talher. O que sobrou da entrada é retirado da mesa para dar lugar ao prato principal, quente, chamado de plat de résistance. Em geral é apenas um: se for uma massa, do tipo parafuso, ela vem sozinha, sem nenhum tipo de acompanhamento ou molho. Batatas cozidas e servidas bem quentes, idem. No caso das massas e batatas, cortam-se pedacinhos de manteiga, deita-se por cima, os quais se derretem ao calor.

A carne bovina é consumida, mas não com tanta regularidade, como no Brasil. O corte da carne é aprimoradíssimo, os pedaços são grossos, altos, e cada bife, por assim dizer, é levemente grelhado na manteiga. Invariavelmente a carne é mal passada, levada à mesa quase in natura. Bistecas de porco fritas sem sal, alho, ou qualquer outro tipo de condimento são muito apreciados. Quando vem carne ela é servida só, sem nada para acompanhar. Há quem goste de espalhar um pouco de manteiga por cima da carne. Com o prato principal toma-se outro tipo de vinho, não mais o da entrada.

Findo o prato quente, retira-se tudo da mesa, deixando somente pão, manteiga e vinho. Serve-se, em seguida, uma salada de folhas verdes, temperadas com uma mistura de vinagre balsâmico, uma colherinha de mostarda de Dijon, extremamente picante, que em nada lembra a mostarda que se come no Brasil, tudo regado a generosas colheradas do mais fino azeite virgem. Raspam-se as sobras do molho com pão.. 
Logo em seguida chegam os queijos, de muitos formatos, sabores e odores, escolhidos entre as quatrocentas e tantas variedades das quais se gabam os franceses. O camembert e os de cabra, de sabor acentuado, nunca ficam de fora. Para comê-los, passam manteiga em pedacinhos de pão e, sobre eles, as talhadas finas de queijo. Prova-se um por vez. Os queijos se vão, desocupa-se a mesa para que venha a sobremesa. Frutas (laranja, melancia, ameixa, cereja ou fatias de abacaxi enlatado, as mais comuns), sorvete (menos freqüente), iogurte de frutas ou natural com um torrão de açúcar, alguma torta: as opções não são tão variadas como na entrada e prato principal. O café, que vem por último, é feito na hora, geralmente em cafeteira elétrica. Normalmente preferem-no puro, encorpado e sem açúcar. No pires do café costumam pôr um pequeno tablete de chocolate ou uma trufa.

Comparando com o almoço em casa de uma típica família brasileira, temos alguma semelhança na distribuição: essa refeição é servida por volta das 12 horas, é a principal do dia, tende a ser mais substanciosa que o jantar. Quanto ao sentido, o almoço francês é similar ao brasileiro, se prestando a nutrir o indivíduo para o restante da jornada do dia. Busca-se reunir em torno da mesa todos os membros da família, apesar de que se estabelece cada vez mais a cultura da comida rápida, os lanches e sanduíches ingeridos às carreiras na rua ou dentro dos metrôs. Herança da sociedade industrializada, o chamado fast food se dissemina a passos largos pelo resto do mundo, incluindo aí o Brasil e a França, mas parece preocupar mais à sociedade francesa, zelosa que é de sua boa mesa.

Ainda com relação ao sentido, em ambas as culturas o almoço de todo dia pode ser substituído por um cardápio especial, em comemoração a uma data qualquer. Na França, no dia de Reis, por exemplo, comemorado no início de janeiro, substitui-se a sobremesa do dia-a-dia por uma torta. Dentro dela vem um brinde em formato de coroa de rei, símbolo de boa sorte para quem a encontra. Já no almoço de Natal, ou no do réveillon, come-se o famoso foie gras (patê de fígado de pato ou ganso), ostras e demais frutos do mar.

Equivalentes no sentido e distribuição, o almoço nas duas culturas difere na forma. Ao olhar de um brasileiro, o almoço francês não deixa de ter um toque refinado, mesmo em casas de famílias comuns da classe média. Comparado a um almoço brasileiro trivial num dia de semana, parece formal, beira o clássico. Têm-se a impressão 
de que é longo o tempo que se passa à mesa. Parece que se come muito, mas levanta-se da mesa leve. O prato principal parece pouco substancioso. O pão e, sobretudo, a manteiga (no Brasil esta nunca se come na hora do almoço), chamam a atenção pelo destaque durante toda a refeição. Mas são os queijos e os vinhos que estabelecem uma fronteira nítida entre as refeições nas duas culturas. No Brasil, queijos e vinhos fazem parte de ocasiões especiais, geralmente no inverno, em casa de pessoas que, se não mais intelectualizadas, possuem uma situação financeira confortável, dados os preços a que são comercializados os referidos itens. Sem contar que, mesmo considerando os custos, esses produtos carecem de variedades no mercado local, somente sendo encontrados em setores especializados, geralmente em grandes cidades. Junte-se a isso o clima brasileiro, nada propício ao consumo de alimentos que pedem temperaturas amenas. Queijo, no Brasil, costuma fazer parte do café da manhã ou do lanche da tarde, o que não é costume em casas francesas. Causa a eles particular espanto saber que uma das sobremesas mais populares no Brasil, o clássico romeu-e-julieta, é composto por queijo fresco branco com goiabada cascão. Queijo com doce seria, na cultura gastronômica francesa, uma combinação no mínimo impensável, talvez até uma aberração, quase um sacrilégio, podendo mesmo causar engulhos.

A diferença também é marcada a olhos vistos pelo entra-esai dos pratos, a distribuição sistemática deles durante a refeição, enquanto no Brasil a mesa é bem guarnecida, farta, e os pratos quentes, muitos deles, em grandes quantidades, são arranjados lado a lado com as saladas. Mete-se tudo no prato, os frios e os quentes, sem distinção. Tudo fica misturado, e não se carrega nada embora até que todos estejam saciados. Na hora da sobremesa, aí sim, retiram-se panelas, travessas, pratos e talheres. E eis que chegam os doces, açucarados a se lambuzar e lamber os beiços: é muita ambrosia, pudim de leite, babade-moça, quindim, cubos de mamão, abóbora e coco em calda muito grossa, sobremesas de sabor acentuado, marcadas, talvez, pela importância histórico-social da cana-de-açúcar no Brasil.

De tudo isso, nada é tão representativo na cultura brasileira do que a dupla arroz-e-feijão, presente em casas de todas as esferas sociais. Os franceses têm alguma dificuldade em entender a razão que leva os brasileiros a comer todo dia no almoço e no jantar a mesma coisa, variando apenas o que popularmente se chama de "mistura". Se 
a diversidade de produtos agrícolas cultivadas no país é tão grande, por que teima sobreviver a monotonia na mesa, questionam-se eles. Do mesmo modo estranham o nosso ponto de cozimento da carne, a abundância dela, as bistecas encorpadas, os bifes acebolados, a picanha vistosa, a costela com mandioca, tão comum nas refeições brasileiras, e que diferem sobremaneira dos hábitos alimentares dos franceses, que os consideram pesados demais para o seu paladar.

De qualquer forma, tudo o que causa estranheza a um brasileiro, encontra equivalente do lado de lá. Somente a título de ilustração, o sujeito-informante, por tratar-se de um jornalista, mais de uma vez inquiriu franceses (falantes de português) acerca daquilo que acham mais difícil de assimilar na cultura brasileira. Entre tantas observações, um deles apontou para o hábito de não comer toda a comida que se coloca no prato. Pensamos que talvez, em função das guerras que conheceram, da comida racionada daqueles tempos, os europeus não admitam que se jogue nada fora. $\mathrm{O}$ informante francês considerou igualmente curioso o costume, especialmente entre as crianças, de dizer: "servido?".

Muito ainda poderia se falar sobre as diferenças e semelhanças entre as duas culturas: a freqüência dos banhos, sempre lembrada pelos brasileiros, a arquitetura das casas e a repartição interna dos cômodos, os utensílios da vida cotidiana, o contato interpessoal e tantas outras coisas; contudo, queremos crer que o panorama que foi aqui traçado tenha aberto caminho para a melhor compreensão dos diversos fatores que levam os sujeitos a cometer inadequações, a avançar em etapas do aprendizado, a recuar quando se vêem forçados por algum tipo de obstáculo, a transferir regras e construções da língua nativa para a língua alvo, a construir uma gramática pessoal baseada em estratégias especialmente voltadas para determinadas situações.

Tudo o que foi dito aqui serve para demonstrar que a aquisição e a aprendizagem de uma segunda língua está intimamente ligada a um conjunto de fatores inerentes a cada realidade sociocultural, e isso deve ser seriamente considerado pelos profissionais da área. E, ainda, para assimilar o fato de que, dada toda a complexidade envolvida no processo de ensino-aprendizagem de línguas estrangeiras, urge que as teorias lingüísticas precisam apoiar-se em subsídios da pedagogia, da sociologia, da filosofia e da psicologia, entre outras ciências, para melhor entender o desenvolvimento de uma segunda língua. 


\section{Considerações finais}

Tentamos, no decorrer do texto, manter a devida objetividade que se espera de um trabalho científico, se é que isso é possível, se é que a imparcialidade realmente pode ser mantida. Contudo, por se tratar de um estudo de caso particular, temos dúvidas quanto ao êxito de nosso intento. De toda maneira, trabalhamos no sentido de apresentar os presentes dados com o máximo de isenção, procurando não nos afastar dos preceitos da Lingüística Contrastiva.

A análise de alguns aspectos da relação entre o português como língua materna e do francês como língua estrangeira à luz da LC não foi o único objetivo deste trabalho.

O sujeito-informante relatou que, após ter se inteirado de alguns dos pressupostos da Lingüística Contrastiva, pôde compreender algumas das etapas percorridas no aprendizado da língua francesa. Relatou, ainda, que, inicialmente, pensava que algumas sensações eram próprias de sua personalidade, mas, para sua surpresa, descobriu que muito dos sentimentos confusos e contraditórios que experimentava, outros aprendizes de línguas também haviam conhecido. É o caso do escritor Rubem Braga, que na crônica "A que partiu" (cf. anexo), fala da estranheza que lhe causou o verbo partir, em francês. No texto, escrito na Paris dos anos 50, o autor relata a angústia que sentiu quando ouviu pela primeira vez alguém dizendo: Elle n'est pas là, monsieur. Elle est partie. Braga entendeu que ela, a mulher em questão, não estava lá, tinha partido para longe, talvez tivesse tomado um trem rumo a um destino desconhecido. Tinha-se ido para nunca mais, assim entendeu Braga. É que para nós, brasileiros, o verbo "partir" encerra em si qualquer coisa de definitivo. "Partir", em português, é um ato derradeiro. Partidas são sempre dolorosas, remetem a despedidas, pressupõem rupturas, lacunas, retornos longínquos a se perder de vista. Viera Braga a saber, após remoer sua dor, que o verbo partir, mesmo escrito tal e qual em português, na língua francesa é mais empregado com o sentido de sortir, ou seja, "sair", "ir embora". Quando Braga ouviu a frase elle est partie, deveria ter entendido que "ela saiu", o que, na língua portuguesa, faz pensar que ela deve voltar dali a pouco. O cronista, ao expor sua experiência, nada mais fez do que fornecer um breve e belo dado para a Lingüística Contrastiva.

Os aprendizes de LE, como Rubem Braga, pegam-se, muitas vezes, presos em pequenas "armadilhas", amarram seus pés em 
alçapões, vêem-se impedidos de se desprender dos laços de sua língua, angustiados por não conseguirem avançar, dominar outro idioma. Sentem que a língua materna, a identidade que diferencia um sujeito de outro sujeito, que empresta segurança e o fortalece, nesse novo contexto, ao contrário, o enfraquece.

Mas, um dia, quando estava com o rádio ligado, o sujeitoinformante conseguiu perceber na fala da locutora uma palavra nunca antes ouvida pronunciar: cerf-volant, em português, "pandorga", "pipa", "papagaio". Naquele momento, não soube a quais desses significados pensou, mas fosse o que fosse, entendeu do que falava a repórter na rádio francesa. A linha da pandorga foi se esticando, esticando, até perceber que estava sendo entrevistado um escritor. Foi compreendendo que ele era afegão, que vivia exilado nos Estados Unidos, e que o livro contava a história de dois meninos, da amizade entre eles, que o pano de fundo era a história do Afeganistão. Uma palavra vinha ligada a outra, as falas foram se amarrando, e o sujeitoinformante a seguia de perto, como se a linha do "cerf-volant" lhe desenrolasse os sentidos. Compreendia pela primeira vez um texto falado em língua francesa, trazida ela por um "cerf-volant" feito de papel de seda, aros finos de madeira e uma longa linha que subia e subia.

Quando voltou ao Brasil, o sujeito-informante viu numa livraria a capa de um livro, em tons de laranja, com o seguinte título: "O caçador de pipas". Entendeu ser ele o "Les cerfs-volants de Kaboul", cuja história tinha ouvido em um programa de rádio. Lembrou-se então daquela manhã fria, "du ciel gris", do rádio ligado, de sua figura diante da janela, da cortina cor de magnólia, de seu hálito embaciando a vidraça, das pessoas que passavam na calçada, encolhidas em seus sobretudos, das árvores desnudadas de suas folhas, e da vOz da repórter que lhe apresentou pela primeira vez um "cerf-volant".

\section{Anexo}

\section{A que partiu}

É uma doçura fácil ir aprendendo devagar e distraidamente uma língua. Mas às vezes acontece uma coisa triste, e a gente sem querer acha que a língua é que está errada, nós é que temos razão. 
Eu tinha há muito, na carteira, o número de telefone de uma velha conhecida, em Paris. No dia seguinte ao de minha chegada disquei para lá. A voz convencional e gentil de uma "concierge" respondeu que ela não estava. Perguntei mais alguma coisa, e a voz insistiu:

Elle n'est pas là, monsieur. Elle est partie.

Eu não tinha grande interesse no telefonema, que era apenas cordial. Mas o mecanismo sentimental de uma pessoa que chega a uma cidade estrangeira é complexo e delicado. Eu esperava ouvir do outro lado aquela voz conhecida, trocar algumas frases, talvez combinar um jantar "qualquer dia destes". Daquele número de telefone parisiense na minha carteira eu fizera, inconscientemente, uma espécie de ponto de apoio, e ele me falhara.

Então me deu uma súbita e desrazoável tristeza; a culpa era do verbo. Ela tinha "partido". Imaginei-a vagamente em alguma cidade distante, perdida no nevoeiro dessa manhã de inverno, talvez em alguma estação da Irlanda ou algum "hall" de hotel na Espanha. Não, sua presença para mim não tinha nenhuma importância; mas tenho horror de solidão, fome de criaturas, sou dessas pessoas fracas e tristes que precisam confessar, diante da auto-suficiência e do conforto íntimo das outras: sim, eu preciso de pessoas; sim, tal como aquele personagem de não sei mais que comédia americana, "I like people".

E subitamente me senti abandonado no quarto de hotel, porque ela havia partido; esse verbo me faria, com seu ar romântico e estúpido, e me fazia pobre e ridículo, a tocar telefone talvez com meses ou anos de atraso para um número de que ela talvez nem se lembrasse mais, como talvez de mim nem mesmo nem se lembrasse, e se alguém lhe dissesse meu nome seria capaz de fazer um pequeno esforço, franzindo as sobrancellhas:

__ Ah, sim, eu acho que conheço.

Mas a voz da "concierge" queria saber quem estava falando. Dei o meu nome. E me senti ainda mais ridículo perante aquela "concierge" desconhecida, que ficaria sabendo o segredo da minha tristeza, conhecendo a existência de um Mr. Braga que procura pelo telefone uma pessoa que partiu.

Meia hora depois o telefone da cabeceira bateu. Atendi falando francês, atrapalhado - e era a voz brasileira da minha conhecida. Estava em Paris, pois eu não tinha telefonado para ela agorinha mesmo? Sua voz me encheu de calor, recuperada assim subitamente das brumas da distância e do tempo, cálida, natural e amiga. Tinha "partido" para 
fazer umas compras, voltara em casa e recebera meu recado; telefonara para um amigo comum para saber o hotel em que eu estava.

Não sei se ela estranhou o calor de minha alegria, talvez nem tenha notado a emoção de minha voz ao responder à sua. Era como se eu ouvisse a voz da amada e todas as amadas, salva de um naufrágio que parecia sem remédio, em noite escura.

Quando no dia seguinte nos encontramos para um almoço num "bristô", eu já estava refeito; era o mesmo conhecido de sempre, apenas cordial e de ar meio neutro, e ela era outra vez ela mesma, devolvida à sua realidade banal de pessoa presente, sem o prestígio misterioso da mulher que partira.

Custamos a aprender as línguas; "partir" é a mesma coisa que "sortir". Mas através das línguas vamos aprendendo um pouco de nós mesmos, de nossa ânsia gratuita, melancólica e vã.

Paris, janeiro de 1950

Rubem Braga

\section{Referências bibliográficas}

BRAGA, Rubem. 200 crônicas escolhidas. São Paulo: Record, 1993.

CAGLIARI, Luiz Carlos. Alfabetização \& Lingüística. São Paulo: Scipione, 1989.

DURÃO, Adja Balbino de Amorim Barbieri. La Interlengua. Madrid: Arco Libros, 2007

Análisis de errores e interlengua de brasileños aprendices de españoly de españoles aprendices de portugués. Londrina: Eduel, 1999.

HOUAISS, Antonio. Dicionário Houaiss da Lingua Portuguesa. São Paulo: Objetiva, 2001.

LADO, Robert. Introdução à Lingüistica Aplicada. Petrópolis:Vozes, 1971.

ROBERT, P. Le Petit Robert - Dictionnaire de la Langue Française. Paris: Robert, 2004 